\title{
Simple Method for Determination of Short-Chain Organic Acid in Mead
}

\author{
Justyna Dobrowolska-Iwanek
}

Received: 7 November 2014 / Accepted: 8 February 2015 / Published online: 24 February 2015

(C) The Author(s) 2015. This article is published with open access at Springerlink.com

\begin{abstract}
Organic acids present in mead influence its fermentation rate during the production process, its stability and microbiological purity as well as organoleptic properties of the final product. The objective of this work was to validate an analytical method for determination of eight main organic acids in mead using the isotahophoresis with conductivity detection. All the validation parameters indicate high reliability of the method. The recovery rates of all analytes were between 96 and $101 \%$. The precision was equal or less than $2.5 \%$. The isotachophoretic system showed also high sensibility due to low limits of detection and quantification. For all investigated organic acids, limit of detection (LOD) ranged from 0.7 to $4.7 \mathrm{mg} \mathrm{L}^{-1}$ and limit of quantification (LOQ) values ranged between 2.2 and $14.2 \mathrm{mg} \mathrm{L}^{-1}$.
\end{abstract}

Keywords Organic acids · Mead · Isotahophoretic separation

\section{Introduction}

Mead is an alcoholic (9-18 \% v/v of ethanol) traditional beverage, produced by fermentation of diluted (with water and/or fruit juices) honey by using different yeast strains (Pereira et al. 2009; Barata et al. 2011). Depending on dilution factor, there are different types of mead: the finest at 1:0.5 (honey/ water), 1:1, 1:2 and 1:3 (Sroka and Tuszyński 2007).

The chemical composition of mead depends mostly on the composition of raw material which is specified by a floral source, geographical and environmental factors (Dezmirean

J. Dobrowolska-Iwanek $(\bowtie)$

Department of Food Chemistry and Nutrition, Medical College, Jagiellonian University, Medyczna 9, 30-688 Krakow, Poland

e-mail: justyna.dobrowolska-iwanek@uj.edu.pl et al. 2012), added microorganisms, vinification practice which involves addition of various spices, hops and organic acids, as well as the maturation procedure (Gupta and Sharma 2009).

During the mead production process, organic acids play an important role due to their influence on fermentation rate, stability and microbiological purity, as well as organoleptic properties (e.g. flavour) of the product. There are numerous sources of organic acids in mead; however, the main ones are bee honey (the main gluconic acid source), fruit juices and organic acids (citric, tartaric or lactic acid) finally added to the bulk to ensure the optimal acidity of beverage. Moreover, some organic acids (e.g. succinic acid) are produced as byproducts of ethanol fermentation.

Many analytical methods have been developed for determination of organic acids in the alcoholic beverage such as gas chromatography (Voica et al. 2013; Yang and Choong 2001) liquid chromatography techniques (Kotani et al. 2004; Kerem et al. 2004) or electrophoretic methods (Peres et al. 2009; Esteves et al. 2004). Isotahophoresis (ITP) method can be useful and cheap and an alternative tool, which allows to separate and determine short-chain organic acid in mead.

The purpose of this study was to validate the rapid and simple analytical procedure using the isotahophoresis with conductivity detection technique for determination of main organic acids present in mead.

\section{Materials and Methods}

\section{Reagents}

Deionised water of $18 \mathrm{M} \Omega \mathrm{cm}$ was obtained from Milli Ro \& Q water purification system (Merck-Millipore, Billerica, MA, USA). Organic acids used were of analytical standard grade. Caproic acid was obtained from Fluka (Steinheim, Germany); monohydrate citric acid (Piekary Śląskie, Poland); D,L-malic 
acid and succinic acid from Lancaster (Morecambe, England); $95 \%$ formic acid and D-gluconic acid sodium salt from Sigma-Aldrich (France) and L-tartaric acid and $80 \%$ D,Llactic acid from Avantor Performance Materials Poland S.A. (Gliwice, Poland). A 36-38 \% hydrochloric acid was from Baker Analyzed and methylhydroxyethylcellulose (M-HEC) from HERCULES (Prague, Czech Republic), $\beta$-alanine from Merck (Darmstadt, Germany) and L-histidine was from Serva (Heidelberg, Germany); $99.5 \%$ acetic acid was obtained from Chempur (Piekary Śląskie, Poland).

\section{Apparatus}

At the beginning of the present study, the previously reported method of determination of organic acids was modified and adopted to the analysis of mead (Dobrowolska-Iwanek et al. 2014). The previously elaborated method of determination of organic acids in wine could not be directly applied because not all acids found in mead could be separated (e.g. at $\mathrm{pH}=3.5$ analytical signals from formic and tartaric acids overlap). Isotachophoretic separations were performed using the Electrophoretic Analyser EA 202 M (Villa Labeco, Spisska Nova Ves, Slovakia) with the conductivity detector. The system was equipped with sample valve of $30 \mu \mathrm{L}$ fixed volume and two capillary: the pre-separation capillary $(90 \mathrm{~mm} \times 0.9 \mathrm{~mm}$ I.D. $)$ and the analytical capillary ( $160 \mathrm{~mm} \times 0.3 \mathrm{~mm}$ I.D.). The preseparation involved the current of $250 \mu \mathrm{A}$, while the actual separation in the analytical capillary column was performed at $60 \mu \mathrm{A}$ during the initialization phase and at $50 \mathrm{l}$ 'A during the detection phase. The leading electrolyte was $15 \mathrm{mM}$ hydrochloric acid with $0.2 \%$ M-HEC, finally adjusted to $\mathrm{pH} 3.6$ with $\beta$-alanine. The terminating electrolyte contained $5 \mathrm{mM}$ caproic acid and $5 \mathrm{mM}$ L-histidine.

\section{Samples and Sample Preparation}

The samples were purchased from the main mead producer in Poland-"Pasieka Marcin Jaros" (Tomaszów Mazowiecki,
Poland). Two types of mead were investigated, including the following: 1:1 and 1:2 honey-to-water wort (the most frequently purchased in Poland). The samples were diluted 1:20 with deionised water, as the preliminary experiments had shown that in case of non-diluted samples, the concentration of investigated organic acids exceeds the working range of the instrument. The obtained solution of each sample was injected directly into the ITP analyser without any other sample treatment.

\section{Method Validation}

Validation was performed by evaluation of such parameters of the method as: linearity range, limits of detections and quantification, precision and accuracy calculated as the recovery. The acquired zones in the ITP analysis were identified by comparison with step heights of standard solution containing pure compounds (organic acids) and of spiked samples to ensure correctness of identification. For quantification of organic acids, the external calibration curve was calculated by the analysis of calibrators at following concentration levels: $3.125,6.25,12.5,25,50$ and $100 \mathrm{mg} \mathrm{L}^{-1}$ for tartaric, formic, citric, malic, lactic, succinic, acetic and gluconic acids. The linearity range was assessed by plotting zones length corresponding to each analyte against acids concentration and then applying the least squares method for calculation respective correlation coefficients $(R)$. According to the validation protocol, the determination coefficient had to meet the criterion of $R^{2}>0.995$. The precision of the method (expressed by the RSD value) was established by successive analysis of the non-spiked and spiked sample solutions, six independent repetitions for each, at the same working day. The validation criterion for precision was $\pm 2.5 \%$ RSD. The recovery was determined by spiking the sample with known concentrations of analytes at two concentration levels (lower $+25 \%$ amount of analyte, higher $+50 \%$ of analyte amount determined in previous measurement of the same non-spiked samples). The sample prepared in the way described above was
Fig. 1 Isotachophoretic separation of organic acids in a standard mixture of eight acids (isotachophoregram c) and in mead sample (isotachophoregram b). Zone assignments: $L E$ leading electrolyte, 1 tartaric acid, 2 formic acid, 3 citric acid, 4 malic acid, 5 lactic acid, 6 gluconic acid, 7 succinic acid, 8 acetic acid, TE terminating electrolyte
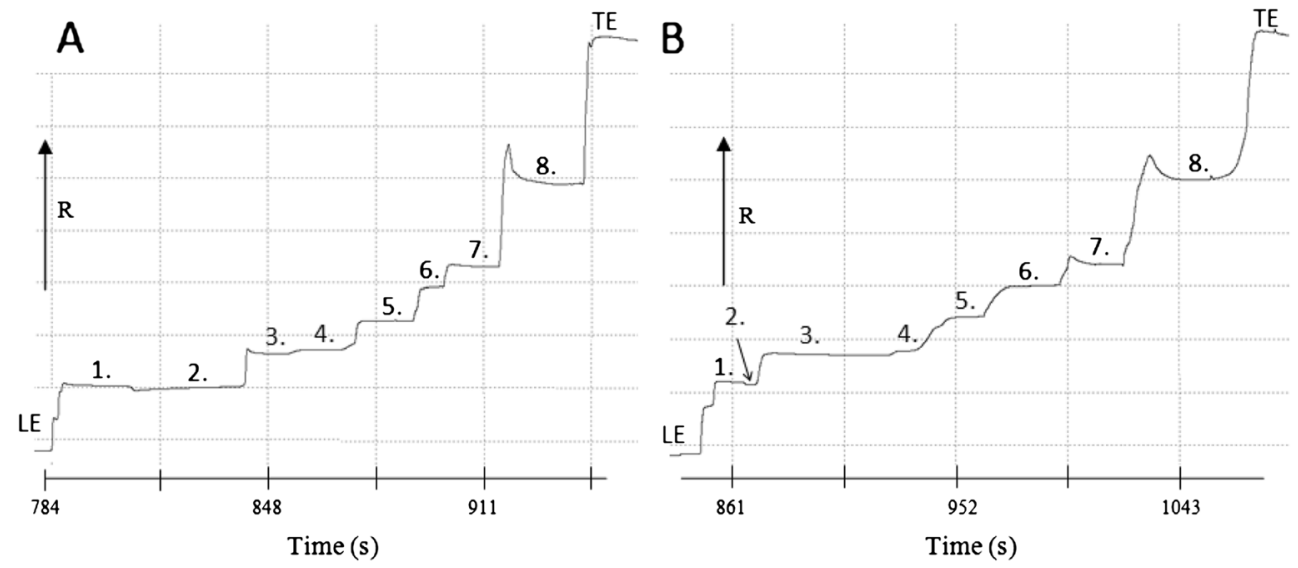
Table 1 Validation parameters for organic acids in mead samples obtained using isotachophoretic method

\begin{tabular}{|c|c|c|c|c|c|c|c|c|c|c|}
\hline \multirow[t]{5}{*}{ Acids } & \multicolumn{2}{|c|}{ Concentration $\left(\mathrm{mg} \mathrm{L}^{-1}\right)$} & \multicolumn{2}{|c|}{ Method accuracy } & \multicolumn{4}{|c|}{ Recovery studies (\%) } & \multirow{2}{*}{\multicolumn{2}{|c|}{$\begin{array}{l}\text { Method precision } \\
\text { Mead worts }\end{array}$}} \\
\hline & & & & & \multicolumn{4}{|l|}{ Mead worts } & & \\
\hline & & & & & \multicolumn{2}{|l|}{$1: 1$} & \multicolumn{2}{|l|}{$1: 2$} & $1: 1$ & $1: 2$ \\
\hline & \multicolumn{2}{|c|}{ Mead worts } & \multirow{2}{*}{$\begin{array}{l}\mathrm{LOD} \\
\left(\mathrm{mg} \mathrm{L}^{-1}\right)\end{array}$} & \multirow{2}{*}{$\begin{array}{l}\mathrm{LOQ} \\
\left(\mathrm{mg} \mathrm{L}^{-1}\right)\end{array}$} & \multirow{2}{*}{$\begin{array}{l}\text { Added amount } \\
\text { level } 1(50 \%)\end{array}$} & \multirow{2}{*}{$\begin{array}{l}\text { Added amount } \\
\text { level } 2(25 \%)\end{array}$} & \multirow{2}{*}{$\begin{array}{l}\text { Added amount } \\
\text { level } 1(50 \%)\end{array}$} & \multirow{2}{*}{$\begin{array}{l}\text { Added amount } \\
\text { level } 2(25 \%)\end{array}$} & \multirow{2}{*}{$\begin{array}{l}\text { RSD } \\
(\%)\end{array}$} & \\
\hline & $1: 2$ & $1: 3$ & & & & & & & & \\
\hline Tartaric & $273 \pm 2$ & $<\mathrm{LOD}$ & 1.1 & 3.4 & $96 \pm 2$ & $101 \pm 1$ & $98 \pm 3$ & $99 \pm 3$ & 0.9 & 0.4 \\
\hline Formic & $59 \pm 2$ & $<\mathrm{LOD}$ & 2.6 & 7.8 & $99 \pm 3$ & $100 \pm 1$ & $98 \pm 3$ & $97 \pm 1$ & 2.0 & 1.3 \\
\hline Citric & $1813 \pm 9$ & $1265 \pm 2$ & 3.8 & 11.4 & $98 \pm 3$ & $99 \pm 1$ & $102 \pm 1$ & $101 \pm 1$ & 0.9 & 0.2 \\
\hline Malic & $271 \pm 5$ & $348 \pm 3$ & 0.7 & 2.2 & $100 \pm 1$ & $99 \pm 1$ & $100 \pm 1$ & $97 \pm 1$ & 2.5 & 1.0 \\
\hline Lactic & $447 \pm 4$ & $348 \pm 6$ & 1.7 & 5.0 & $101 \pm 1$ & $100 \pm 1$ & $98 \pm 1$ & $101 \pm 1$ & 1.4 & 2.3 \\
\hline Gluconic & $1058 \pm 6$ & $549 \pm 3$ & 4.7 & 14.2 & $99 \pm 1$ & $100 \pm 2$ & $96 \pm 0$ & $99 \pm 0$ & 1.2 & 1.1 \\
\hline Succinic & $690 \pm 11$ & $814 \pm 4$ & 1.2 & 3.7 & $97 \pm 1$ & $100 \pm 2$ & $100 \pm 1$ & $98 \pm 1$ & 2.5 & 0.8 \\
\hline Acetic & $611 \pm 13$ & $473 \pm 4$ & 4.7 & 14.2 & $97 \pm 1$ & $97 \pm 3$ & $99 \pm 1$ & $101 \pm 1$ & 1.7 & 0.7 \\
\hline
\end{tabular}

submitted to measurement for five times. According to the validation protocol, the recovery values should fit the range 95-105\%. The limit of detection (LOD) and limit of quantification (LOQ) for each organic acid were calculated based on the residual standard deviation (SD) of the analytical signal and slope of the calibration curve(s), according to the formulas: $\mathrm{LOD}=3.3 \mathrm{SD} / \mathrm{s}, \mathrm{LOQ}=10 \mathrm{SD} / \mathrm{s}$, respectively.

\section{Results and Discussion}

The proposed isotachophoretic method allowed the isolation of eight acids in mead samples with satisfactory resolution. The isotachophoregrams of a standard mixture solution and the example mead sample are presented in Fig. 1. The analytical range was found to be linear from 3.125 to $100 \mathrm{mg} \mathrm{L}^{-1}$ with high correlation coefficients of calibration curves $R>$ 0.998 . The calculated validation parameters were collected in Table 1 . The recovery rates of all analytes were between 96 and $101 \%$. The obtained recovery range was comparable to this obtained by Dezmirean et al. (2012), who determined organic acids in fermented products obtained from Romanian honey using HPLC method (95-105\%). The precision, which involved repeatability of analysis $(n=6)$, was evaluated using a mead sample and spiked mead samples (as mentioned above). Relative standard deviation value of the zone length was equal or less than $2.5 \%$. The results were slightly higher than those reported by Dezmirean et. al. (01-09\%), but complied with validation criterion of precision. The isotachophoretic system showed also high sensibility due to low limits of detection and quantification. For all investigated organic acids, LOD ranged from 0.7 to $4.7 \mathrm{mg} \mathrm{L}^{-1}$ and LOQ values ranged between 2.2 and $14.2 \mathrm{mg} \mathrm{L}^{-1}$ whereas LOD and
LOQ determined by Dezamirean et. al. were in the range $0.50-8.32$ and 1.62-18.25, respectively, but expressed in milligrammes per kilgramme.

The reliable and cheep isotahophoresis method with conductivity detector, described in this study, enabled to determine eight organic acids in a mead sample. All the validation parameters indicate high reliability of the method. Moreover, sample preparation is fast and simple, needing only dilution before injection. The proposed method makes possible to monitor changes in the composition profile and the concentration of organic acids during the mead wort fermentation, as well as it enables to control the maturity of the final product. Furthermore, it can be used to test commercial mead available in the market in order to detect the presence of organic acids from other sources than mead and fermentation process (e.g. from fruit juices or organic acid additives).

\section{Compliance with Ethics Requirements}

Conflict of Interest Justyna Dobrowolska-Iwanek declares that she has no conflict of interest. This article does not contain any studies with human or animal subjects.

Open Access This article is distributed under the terms of the Creative Commons Attribution License which permits any use, distribution, and reproduction in any medium, provided the original author(s) and the source are credited.

\section{References}

Barata A, Campo E, Malfeito-Ferreira M, Loureiro V, Cacho J, Ferreira V (2011) J Agric Food Chem 59(6):2543-2553

Dezmirean GI, Mărghitas LA, Bobiș O, Dezmirean DS, Bonta V, Erler S (2012) J Agric Food Chem 60(32):8028-8035 
Dobrowolska-Iwanek J, Gąstoł M, Wanat A, Krośniak M, Jancik M, Zagrodzki PS (2014) Afr J Enol Vitic 35(1):1-9

Esteves VI, Lima SSF, Lima DLD, Duarte AC (2004) Anal Chim Acta 5131:163-167

Gupta JK, Sharma R (2009) Nat Prod Radiance 8(4):345-355

Kerem Z, Bravdo BA, Shoseyov O, Tugendhaft Y (2004) J Chromatogr A 1052(1-2):211-215

Kotani A, Muyaguchi Y, Tomita E, Takamura K, Kusu F (2004) J Agric Food Chem 52(6):1440-1444
Pereira AP, Dias T, Andrade J, Ramalhosa E, Estevinho LM (2009) Food Chem Toxicol 47(8):2057-2063

Peres RG, Moraes EP, Micke GA, Tonin FG, Tavares MFM, Rodriguez-Amaya DB (2009) Food Control 20:548-552

Sroka P, Tuszyński T (2007) Food Chem 104(3):1250-1257

Voica C, Kovacs M, Vadan M (2013) Processes in Isotopes and Molecules. AIP Conf Proc 1565(1):313-316

Yang M-H, Choong Y-M (2001) Food Chem 75(1):101-108 